\title{
María Rosa Gudiño Cejudo, Educación higiénica y cine de salud en México 1925-1960, México, El Colegio de México, 2016, 256 pp.
}

¿Por qué los gobiernos pos-revolucionarios se preocuparon en ofrecer servicios de salud y crear una cultura de higiene nacional? ¿De qué medios se sirvió el Estado mexicano para difundir tan novedoso mensaje? y ¿Cómo es que la propaganda dirigida a incidir en los hábitos cotidianos se convirtió en un puente que vinculó al discurso médico con la cultura de los receptores mayoritariamente campesinos? En su más reciente libro, la historiadora María Rosa Gudiño Cejudo responde a estas interrogantes desde la historia social y cultural de la salud pública. Su investigación sostiene que la propaganda sanitaria además de haber fungido como un instrumento de persuasión paternalista del Estado, abrió un espacio para la convergencia de múltiples actores y esfuerzos que -motivados por intereses diversos- apoyaron el proyecto médico-cultural modernizador.

En cuanto a la labor gubernamental, la autora indica que la política estatal de “reconstrucción nacional” - desde la presidencia de Plutarco Elías Calles hasta el gobierno de Adolfo Ruíz Cortines- impulsó ambiciosas campañas de salud y educación higiénica sin precedente en la historia nacional. Así, a través del diseño de propaganda oral, escrita y audiovisual se lanzaron las recomendaciones modernizadoras; apoyadas en la creación de programas radiofónicos, folletos, carteles, exposiciones, congresos y cine.

El libro de Gudiño Cejudo desarrolla la relación entre las campañas de educación higiénica y el cine de salud, entendiendo a éste como un soporte de difusión que combinó las intenciones educativas y propagandísticas del gobierno al tiempo que se convertía en la alternativa ideal para informar a una población con un alto porcentaje de analfabetismo. 
Además, la autora incluye un análisis del papel de los creadores de estas cintas: dibujantes, fotógrafos, museógrafos y cineastas.

Con estas metas, la investigación de Gudiño Cejudo se distingue de otras pesquisas que en la indagación sobre los procesos de modernización se han ocupado prioritariamente en el estudio del funcionamiento institucional, desdibujando así, el papel activo de los ejecutores del proyecto y, aún más grave, diluyendo las reacciones de los receptores quienes por lo general han sido retratados como sujetos pasivos. En suma, la propuesta contribuye de manera original a complejizar la discusión desde la que se han desarrollado los estudios de educación higiénica. Igualmente, el libro tiene el mérito de convocar a un público amplio que incluye tanto a los estudiosos de la historia y disciplinas a fines, como a los profesionales de las ciencias médicas y biológicas; aportando así, a abrir espacios y temas de diálogo interdisciplinario, imprescindibles para la profundización del conocimiento sobre el pasado.

La historiadora centra su análisis en tres campañas realizadas entre 1925 y 1960, estas son: la Campaña Nacional contra las Enfermedades Venéreas (1927), Salud para las Américas (1943-1950) y la Campaña Nacional de Erradicación del Paludismo (1957). La tríada muestra los márgenes de acción de estas campañas que se movieron entre lo internacional, lo nacional y lo regional. Es por ello que el libro refiere las coyunturas nacionales e internacionales que incidieron en la conformación de las campañas, de la mano de la consideración de los avatares en la formación del Estado heredero de la Revolución Mexicana. Igualmente, la investigación da cuenta de la manera en que las campañas sirvieron para integrar a la población a las nuevas instituciones entre lo local y lo federal.

Las campañas analizadas fueron encabezadas por el Departamento de Salubridad (DSP), la Secretaría de Salubridad y Asistencia (SSA) y la Secretaría de Educación Pública (SEP). Estas instituciones estaban convencidas de que la erradicación de epidemias se lograría 
mediante la enseñanza de medidas de prevención y campañas de vacunación encaminadas a propiciar la asimilación de consejos higiénicos que según su opinión privaban del bienestar a la población más empobrecida. Así, este mensaje se enlazó con la aseveración de que el avance de la modernización del país se encontraba condicionado al saneamiento.

El material filmográfico que la historiadora refiere proviene de distintos repositorios, entre los que destacan en México: el Acervo Histórico del Instituto Nacional de Salud Pública, el Archivo Histórico de la Secretaría de Educación Pública, el Archivo Histórico de la Secretaría de Salud y la Filmoteca de la Universidad Nacional Autónoma de México. Mientras que en Estados Unidos sobresalen: la National Library of Congress y los National Archives and Records Administration. Asimismo, el estudio de estas fuentes se complementó con la consulta de documentos provenientes de la Oficina de Asuntos Inter-americanos y la revisión de testimonios de médicos, sanitaristas y maestros rurales que encabezaron las campañas y tuvieron la responsabilidad de difundir la educación higiénica, lo que en conjunto permitió a la autora aproximarse a la recepción de las películas entre el público.

Además, la investigación abarca el estudio del proceso de organización de las campañas y la reflexión sobre las representaciones cinematográficas diseñadas para difundir su programa. Es por esto que la autora se pregunta por los estereotipos que conformaron la imagen de los receptores, que en la mayoría de los casos fueron retratados como campesinos enfermos, atrasados, ignorantes, flojos y sucios. De manera que la propaganda sugería que los campesinos a través de su participación en las campañas podrían convertirse en individuos limpios, fuertes y sanos, capaces de ser el cimiento de la modernización del país; la autora indica que se trata claramente de una imagen idealizada y "blanquedada”. Debido a esto, la filmografía enfatizó el contraste entre la salud y la enfermedad; primero, acompañado de una diferenciación entre niños y adultos, y después, entre los hombres jefes de familia y las mujeres amas de casa. Estas 
representaciones se complementaron con las de médicos, agentes sanitarios, enfermeras, rociadores y notificantes, convertidos en modelos sanitarios.

Para la autora, este nuevo espacio de labor sanitaria mostró que las campañas de salud requerían de un amplio trabajo capaz de integrar al estudio de las enfermedades el análisis del contexto ambiental, social y cultural de los receptores, lo que significó la inclusión del trabajo interdisciplinario — no siempre armonioso- entre biólogos, enfermeras, agrónomos, maestros rurales, antropólogos y médicos. Estos últimos lograron una mayor compenetración en el medio rural a partir del establecimiento del servicio social obligatorio para los médicos pasantes a partir de 1936, dicha medida tuvo el doble objetivo de extender la cobertura del servicio médico al tiempo de intentar abolir la práctica de la medicina tradicional.

La Campaña Nacional contra las Enfermedades Venéreas (1927) estuvo dirigida a la atención de la sífilis, una enfermedad que —según su promotor Bernard Gastélum— afectaba a casi el $60 \%$ de la población mexicana. Entre la filmografía destacan: Al final del camino dirigida por Edward H. Griffin, El precio de un desliz producida por Columbia Pictures, y Reconquista, un cortometraje mexicano realizado por la SSA. Aunque las tramas se distinguen, las tres tuvieron el objetivo de mostrar a los portadores de la sífilis las consecuencias de llevar una vida desordenada, cuya situación sólo podía ser remediada mediante la corrección de conducta y atención médica. Se trata de un mensaje moralizante que buscaba refrenar las conductas consideradas escandalosas dentro del segmento más conservador. Además, la propaganda sirvió para reforzar la estigmatización de las bailarinas de salón y las prostitutas, consideradas la principal causa de propagación del mal venéreo; en contraposición, la autora destaca que los hombres fueron representados como víctimas.

A diferencia de la anterior, la campaña Salud para las Américas (1943-1950) fue resultado de la presencia estadounidense en México que a través de la Fundación Rockefeller Secuencia, e-ISSN 2395-8464 
apoyó los primeros intentos por federalizar la salud. Así, el escenario internacional que enmarcó esta campaña fue la Segunda Guerra Mundial mientras que el ámbito institucional fue configurado por la política de buena vecindad de los Estados Unidos hacia América Latina. Esta labor fue acompañada de manera constante por la colaboración de la Oficina de Asuntos Inter-americanos que bajo la dirección de Nelson Rockefeller recalcó la importancia de las campañas de salud para el mantenimiento de la paz en la región, lo que reforzaba el argumento esgrimido desde Estados Unidos de su papel como defensor del continente.

Como resultado, el diseño de los contenidos se convirtió en el medio idóneo para superponer al discurso sanitario la promoción de la unidad latinoamericana como estrategia para la defensa del continente frente al fascismo y el comunismo. A través de la implementación de un vocabulario militar y del uso de metáforas y analogías el discurso cinematográfico equiparó la lucha contra las enfermedades con la guerra sin tregua en contra el Eje fascista. Dichas realizaciones quedaron a cargo del director y animador Walt Disney, el fotógrafo Herbert Knapp y el productor Jack Chertok. Al mismo tiempo, las campañas sirvieron para promover el uso de productos químicos para el tratamiento médico, entre los que destacaron el DDT y el dieldrín, ambos asociados a la economía norteamericana.

Por lo que se refiere a la Campaña Nacional de Erradicación del Paludismo (1957) la autora indica que fue la respuesta del gobierno mexicano a la convocatoria de la Organización Mundial de la Salud para la erradicación global del paludismo. En este caso, la cobertura cinematográfica quedó a cargo de la Sección de Educación Higiénica de la SSA, entre ellos sobresalen los cortometrajes: Guerra al paludismo, Cruzada heroica y Erradicación del paludismo en México. Uno de los mensajes más destacados de estos materiales es la continuidad en el uso del lenguaje geopolítico según el cual, los intermediarios de las campañas eran los "soldados de la salud” mientras que todo aquél mexicano que abriera su casa para 
participar de la campaña se convertía en un verdadero patriota que contribuía a forjar un país sano y laborioso.

En definitiva, el libro de María Rosa Gudiño Cejudo constituye una valiosa aportación, toda vez que los programas de educación higiénica y su propaganda han sido un tema poco analizado por los historiadores de la salud pública, esto debido a que el foco de atención se ha centrado en la indagación sobre la historia de los médicos e instituciones. Además, la propuesta de la autora se suma a una corriente que se ha ocupado en desarrollar investigaciones que diluyan el escepticismo -aún asentado en algunos ámbitos- de usar las imágenes en movimiento como una fuente de valor para la investigación histórica. No obstante, el libro sugiere diversos temas que aún quedan pendientes de ser desarrollados, entre ellos: el papel de la radio en la difusión del mensaje higiénico, el aspecto comercial de las campañas sanitarias y la oposición campo/ciudad en los discursos modernizadores.

Asimismo, conviene subrayar que aunque esta investigación aporta de manera innovadora al conocimiento sobre la creación, introducción y recepción de las prácticas sanitarias en México, aún hay un extenso campo para indagaciones que problematicen sobre los efectos a largo plazo de la implementación de modelos de desarrollo sanitario diseñados en el extranjero. Más trabajos de este tipo permitirán evaluar los resultados de los proyectos de cooperación que en materia de educación, salud y agricultura entabló México junto a Estados Unidos y otras instancias internacionales. Se trata de un tema de primera importancia debido a que la participación de México en estos programas convirtió al país en un laboratorio de las nuevas prácticas que posteriormente fueron exportadas al resto de América Latina.

Diana Alejandra Méndez Rojas Instituto de Investigaciones Dr. José María Luis Mora, México damendezr@institutomora.edu.mx 